\title{
Medication Regimen Complexity In 8 Australian Residential Aged Care Facilities: Impact Of Age, Length Of Stay, Comorbidity, Frailty, And Dependence In Activities Of Daily Living
}

This article was published in the following Dove Press journal:

Clinical Interventions in Aging

\section{Esa YH Chen (D) ${ }^{1,2}$ \\ J Simon Bell ${ }^{1-3}$ \\ Jenni llomaki $\mathbb{D}^{2,3}$ \\ Claire Keen (ID) \\ Megan Corlis ${ }^{2,4}$ \\ Michelle Hogan ${ }^{4}$ \\ Jan Van Emden ${ }^{2,4}$ \\ Sarah N Hilmer ${ }^{2,5}$ \\ Janet K Sluggett $\mathbb{D}^{1,2}$}

'Centre for Medicine Use and Safety, Faculty of Pharmacy and Pharmaceutical Sciences, Monash University, Parkville, VIC, Australia; ${ }^{2} \mathrm{NHMRC}$ Cognitive Decline Partnership Centre, Hornsby Kuring-gai Hospital, Hornsby, NSW, Australia; ${ }^{3}$ Department of Epidemiology and Preventive Medicine, School of Public Health and Preventative Medicine, Monash University, Melbourne, VIC, Australia; ${ }^{4}$ Helping Hand Aged Care, North Adelaide, SA, Australia; ${ }^{5}$ Kolling Institute, Faculty of Medicine and Health, The University of Sydney and Royal North Shore Hospital, St Leonards, NSW, Australia
Correspondence: Esa YH Chen Centre for Medicine Use and Safety, Faculty of Pharmacy and Pharmaceutical Sciences, Monash University, 38I Royal Parade, Parkville, VIC 3052, Australia $\mathrm{Tel}+61399039533$

Email Esa.Chen@monash.edu
Objective: To explore variation in medication regimen complexity in residential aged care facilities (RACFs) according to resident age, length of stay, comorbidity, dementia severity, frailty, and dependence in activities of daily living (ADLs), and compare number of daily administration times and Medication Regimen Complexity Index (MRCI) as measures of regimen complexity.

Methods: This study was a cross-sectional analysis of baseline data from the SImplification of Medications Prescribed to Long-tErm care Residents (SIMPLER) cluster-randomized controlled trial. The SIMPLER study recruited 242 residents with at least one medication charted for regular administration from 8 RACFs in South Australia. Comorbidity was assessed using the Charlson Comorbidity Index (CCI). Dementia severity was assessed using the Dementia Severity Rating Scale. Frailty was assessed using the FRAIL-NH scale. Dependence in ADLs was assessed using the Katz ADL scale.

Results: The median age of participants was 87 years (interquartile range 81-92). Over onethird of participants $(n=86,36 \%)$ had 5 or more daily medication administration times. The number of daily administration times and MRCI scores were positively correlated with resident length of stay $\left(r_{s}=0.19 ; 0.27\right)$, FRAIL-NH score $\left(r_{s}=0.23 ; 0.34\right)$ and dependence in ADLs $\left(r_{\mathrm{s}}=-0.21 ;-0.33\right)$ (all $\left.\mathrm{p}<0.01\right)$. MRCI was weakly negatively correlated with CCI score $\left(r_{s}=-0.16 ; p=0.013\right)$. Neither number of daily administration times nor MRCI score were correlated with age or dementia severity. In multivariate analysis, frailty was associated with number of daily administration times (OR: 1.13, 95\% CI: 1.03-1.24) and MRCI score (OR: 1.26, 95\% CI: 1.13-1.41). Dementia severity was inversely associated with both multiple medication administration times (OR: 0.97, 95\% CI: 0.94-0.99) and high MRCI score (OR: 0.95, 95\% CI: 0.92-0.98).

Conclusion: Residents with longer lengths of stay, more dependent in ADLs and most frail had the most complex medication regimens and, therefore, may benefit from targeted strategies to reduce medication regimen complexity.

Keywords: Aged, nursing homes, medication regimen complexity, frailty index, activities of daily living, multimorbidity, long-term care facilities

\section{Plain Language Summary}

This study analyzed data collected from 242 residents from 8 residential aged care facilities (RACFs) in South Australia. We were interested in the characteristics of residents with differing levels of medication regimen complexity. The complexity of a medication regimen 
depends on the number of medications, the form of medications, how often the medications need to be taken, and additional directions for how to take the medications. We measured medication regimen complexity in two different ways: counting the overall number of times medications were given each day and using a previously published scale (the Medication Regimen Complexity Index). The measures gave similar results when the complexity of medication use was examined among residents of varying age, length of stay in the RACF, health conditions, cognitive impairment, frailty and need for help in day-to-day activities. By both measures, residents with longer lengths of stay, were dependent in activities of daily living and had advanced frailty were more likely to have the most complex medication regimens and may benefit the most from targeted strategies to reduce medication regimen complexity.

\section{Introduction}

With more older people now receiving community-based aged care, residents admitted to RACFs are increasingly older, frailer and have more complex care needs. ${ }^{1}$ A review of international literature reported that up to $74 \%$ of residents of long-term care facilities use 9 or more regular medications. ${ }^{2}$ However, there are other factors apart from the number of medications that contribute to a resident's medication burden. Medication regimen complexity is also a contributing factor. Medication regimen complexity includes the number of doses of medications, the medication schedule (i.e. what times the medications are administered), medication formulation (e.g. tablet, patch, inhaler), preparation requirements (e.g. need to crush, mix with thickened fluids or inhaler priming), and special instructions for administration (e.g. take on an empty stomach). ${ }^{3}$

Complex medication regimens are challenging for residents and RACF staff to administer and, therefore, may increase risk of medication administration errors such as administration of the wrong medication, to the wrong resident, or at the wrong time. ${ }^{4-6}$ Medication administration errors in RACFs have been reported to occur during $7.1 \%$ to $24.6 \%$ of observed administration events. ${ }^{7-9}$ Higher medication regimen complexity has been associated with a higher likelihood of medication discrepancies in ambulatory care patients. ${ }^{10}$ Emerging evidence also suggests that complex medication regimens may be associated with medication non-adherence, adverse drug events, hospitalization, hospital readmission, and mortality among RACF residents and in community settings. ${ }^{11-13}$ Simplifying complex medication regimens may help to improve these outcomes for residents. In RACFs, simplification is important from an organizational level to minimize risk of harm from medication errors for residents who often cannot manage their own medications. Complex medication regimens have been associated with an increased risk of hospitalization from RACFs. ${ }^{11}$ Simplification may also benefit staff who administer medication, who may experience frustration over frequent medication administration. ${ }^{4}$

Complexity of medication regimens has been measured using a variety of methods in older people. ${ }^{14}$ The Medication Regimen Complexity Index (MRCI) is the most common method and has been used internationally to characterize complex medication regimens in RACFs. ${ }^{14-17}$ In practice, the MRCI has some limitations. The first is that the MRCI score can be time-consuming to calculate. Automatic methods of calculation have been developed but are not widely accessible. ${ }^{18,19}$ The second is that the MRCI does not specifically account for the overall number of daily administration times. The number of daily administration times reflects the frequency of medication administration organized over 24 hrs. $^{20}$ A United States' (US) study showed communitydwelling older people demonstrate large variability in the number of times they would administer medications each day when presented with the same seven medications. ${ }^{20}$ Fewer studies have investigated number of daily administration times as a measure of complexity. ${ }^{21}$ Reducing the number of daily administration times may improve resident quality of life, satisfaction and convenience, and free up nursing time to focus on other aspects of clinical care. ${ }^{13,22-24}$ Number of daily administration times is an easier measure of complexity to calculate in clinical practice than MRCI.

Increasing awareness of the potential for medicationrelated harm in RACFs has highlighted the need to identify residents with high medication burden who will benefit most from medication management interventions. It is important to understand the prevalence and correlates of complex medication regimens to better target potential interventions, including to those who are frail, dependent in activities of daily living (ADLs) or are living with dementia. Previous studies in community and hospital settings have found scope to simplify medication regimens measured using number of daily administration times. ${ }^{21,25,26}$ However, medication regimen complexity in RACFs has not been explored using number of daily administration times. The objective of this study was to explore variation in medication regimen complexity in RACFs according to resident age, length of stay, comorbidity, dementia severity, frailty, and dependence in ADLs, and compare number of daily administration times and MRCI as measures of regimen complexity. 


\section{Methods}

\section{Study Design And Setting}

This study was a cross-sectional analysis of baseline data collected from the SImplification of Medications Prescribed to Long-tErm care Residents (SIMPLER) study (Australian New Zealand Clinical Trials Registry Trial ID ACTRN12617001060336). ${ }^{27}$ The SIMPLER study is an ongoing cluster-randomized controlled trial conducted in eight metropolitan and rural RACFs in South Australia. In Australia, RACFs are synonymous with "nursing homes" or "long-term care facilities" and provide 24-hour supported accommodation for predominantly older people whose care needs can no longer be supported at home. ${ }^{1}$ The SIMPLER study was approved by the Monash University Human Research Ethics Committee and conducted in accordance with the World Medical Association Declaration of Helsinki. The full SIMPLER study design and methodology have been described previously. ${ }^{27}$

\section{Participants}

Study participants were recruited between April and October 2017. All eligible residents were invited to participate by trained research nurses who were employed as part of the study. Residents were eligible if they took at least one regular medication and were able to complete structured assessments in English. Residents who were estimated to have less than 3 months to live or deemed medically unstable (e.g. experiencing delirium) based on the judgement of senior RACF nursing staff were excluded. Residents could also be excluded at the discretion of the nursing staff or primary physician. Residents provided written informed consent to participate. Where the resident was unable to provide informed written consent, consent to participate was sought from the resident's guardian, next-of-kin, or significant other. ${ }^{27}$

\section{Data Source/Measurements}

Four trained research nurses collected baseline demographic and clinical data using a web-based standard data collection form. Cognitive impairment was assessed using the Dementia Severity Rating Scale (DSRS). This scale consists of 12 cognitive and functional domains and was completed with input from a staff informant. ${ }^{28,29}$ The DSRS is suitable to assess impairments in residents with and without a documented dementia diagnosis. ${ }^{29}$ The DSRS is not a diagnosis tool for dementia and was used to capture the many residents who may have some level of cognitive impairment without a documented dementia diagnosis. ADLs were assessed using the 6-item Katz ADL scale. ${ }^{30}$ The DSRS and Katz ADL scales were completed with input from a staff-informant who had known the resident for at least 2 weeks. Frailty was assessed using the 7-item Fatigue, Resistance, Ambulation, Incontinence or illness, Loss of weight, Nutritional status, and Help with dressing in nursing homes (FRAIL-NH) scale. ${ }^{31,32}$ The FRAIL-NH was constructed from four items from the Katz ADL scale, two items from the Mini Nutritional Assessment Short Form, and one item from the Quality of Life in Alzheimer's Disease Scale. ${ }^{33}$ A score between 6 and 14 was considered indicative of advanced frailty. ${ }^{33}$ Clinical diagnoses were extracted from each participant's medical record of "active" conditions. A Charlson Comorbidity Index (CCI) score was calculated for each participant using the version updated and validated by Quan et al (2011). ${ }^{34}$ We did not weight for age because correlations with age were investigated separately. Where severity of certain diagnoses was not recorded (e.g. the severity of "liver disease" was not recorded), the diagnoses were assumed to be mild. The DSRS, Katz-ADL, FRAIL-NH, and CCI are all validated scales that have been previously used in studies in the RACF setting, allowing comparison with existing literature. ${ }^{28-34}$ Length of stay was calculated from the time of first admission to an RACF within the aged care provider organization to the date of baseline data collection.

\section{Medication Assessment}

Prescription and non-prescription medication data were extracted by hand directly from hard copies of each resident's medication administration chart and recorded in a Microsoft Access (2017) database. ${ }^{18}$ Data extracted included medication name, strength, dose, formulation, frequency of administration, time of administration, and special instructions for administration. Medications were classified using the World Health Organization (WHO) Anatomical Therapeutic Chemical (ATC) classification system. ${ }^{35}$ If a participant was taking two different formulations of the same medication it was counted as two medications. Regular medications were defined as those that were charted for administration on a regular basis with a frequency of administration of at least once weekly.

\section{Outcome}

Medication regimen complexity was assessed using two methods: number of daily administration times and the MRCI. 


\section{Number Of Daily Administration Times}

The overall number of daily administration times was operationally defined as the total number of charted medication administration times over a $24 \mathrm{hrs}$ period for regular mediations. ${ }^{27}$ This was calculated by counting the number of unique times of administration over a $24 \mathrm{hrs}$ period extracted from the medication chart (e.g. 08:00, 17:00). All prescription and non-prescription medications (e.g. multivitamins, complementary and alternative medication) present on their medication administration chart ("charted") for administration daily or more frequently were included, regardless of the dose formulation. The application of once-daily patches (e.g. glyceryl trinitrate patches) was considered to be an administration time while the removal was not. The following were excluded when calculating the number of daily administration times: pro re nata (PRN, or as required) and short-term medications, nutritional drinks, and regular medications administered less than daily (e.g. 6 monthly injections, once weekly tablets, patches applied every third day).

\section{Medication Regimen Complexity Index (MRCl)}

The MRCI is a 65-item validated tool and the most widely used measure of medication regimen complexity. ${ }^{3,14}$ There are three sections that comprise the MRCI score: section A refers to formulation of the medication, section $\mathrm{B}$ refers to frequency of administration, and section $\mathrm{C}$ refers to additional or special instructions for administration. MRCI scores are cumulative for each medication in the regimen, including PRN medication. As such, there is no maximum MRCI score. Higher scores indicate more complex medication regimens. MRCI scores were calculated using SAS statistical software using the data extracted from the resident's medication administration chart. The algorithm used was based on the original $\mathrm{MRCI}^{3}$ with the following updates for new formulations: wafers and oral-disintegrating tablets were given the same value as sublingual sprays/tablets. Soft-mist inhalers, a new formulation introduced since the development of the MRCI, were given the same value as metereddose inhalers, the closest equivalent dose form. There was no information available to assess "take/use as directed" and "tapering/increasing dose" in section C.

It is possible to have medication regimens with the same MRCI score, but a different number of daily administration times. The prescribed frequency of a medication (section B) does not necessarily reflect the overall number of daily administration times. For example, a resident taking two once-daily medications (e.g. candesartan $16 \mathrm{mg}$ once daily and atorvastatin $40 \mathrm{mg}$ once daily) may take both together in a single daily administration time. Alternatively, the resident may separate the doses to two daily administration times by taking candesartan in the morning and atorvastatin in the evening. In this example, the single and separated administration times of two once-daily medications are considered equally complex by the MRCI's Section B. However, two daily administration times are more complex than one daily administration time.

\section{Statistical Analysis}

Demographic data were summarized using medians and interquartile ranges (IQRs). Age, length of stay in the RACF, DSRS score, FRAIL-NH, Katz-ADL score, MRCI score, and number of daily administration times were analyzed as continuous variables. Associations were presented as scatter plots. We reversed the Katz-ADL scale score for presentation in scatterplots by giving points for dependence (rather than independence) in order to assist with interpretation alongside the other scales. Correlations were evaluated using the Spearman correlation coefficient. Univariate and multivariate logistic regression models were performed to calculate odds ratios (OR) and 95\% confidence intervals (CIs) to examine associations between the above continuous variables and multiple administration times (model 1) and high MRCI score (model 2). The outcome of multiple administration times was defined as five or more daily administration times. High MRCI scores were classified as scores in the upper quartile (>55.5). In our multivariate model, we included only FRAIL-NH and not Katz-ADL as the two scales assess frailty and disability, respectively, but have a number of items in common. Analyses were conducted in SAS v 9.4 (SAS Institute, Inc., Cary, NC) and R v 3.5.0 (Comprehensive R Archive Network) with RStudio v 1.1.453. Results were considered significant if $\mathrm{p}<0.05$.

\section{Results}

There were 242 permanent residents recruited from 8 RACFs in South Australia (Figure 1). The median age of participants was 87 years and the age distribution was leftskewed. The sample was representative of the resident population within the wider organization $(n=703)$, in which the median age was 87 years (IQR 81-92), there were 523 females (74\%) and 356 residents were living with dementia $(50.6 \%)$. The recruited sample of residents was also similar to the wider aged care population in Australia with respect to age (62\% vs $59 \%$ aged 85 years 


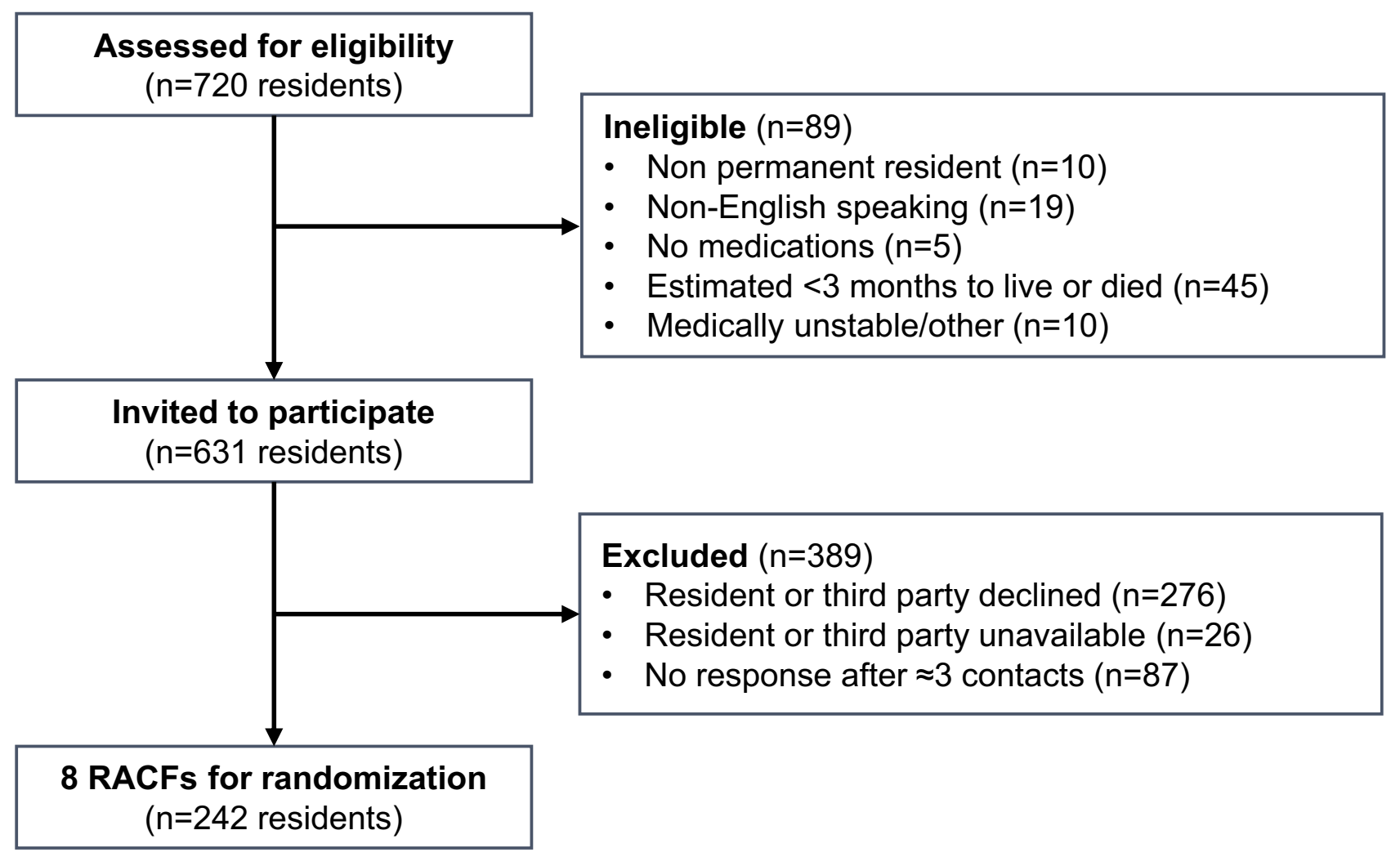

Figure I Study recruitment flow diagram.

Abbreviation: RACFs, residential aged care facilities.

or older), sex ( $74 \%$ vs $67 \%$ female), and length of stay (2.54 years vs 2.92 years). ${ }^{36}$ The sample was also comparable to previous studies in RACFs in Australia with respect to age and length of stay. ${ }^{11,37-39}$

Participants took a median of nine regular medications (IQR 6-12). Over half ( $\mathrm{n}=128,53 \%)$ were taking nine or more regular medications. Number of regular medications was significantly correlated with length of stay $\left(r_{s}=0.13\right.$, $\mathrm{p}=0.04)$ and DSRS score $\left(\mathrm{r}_{\mathrm{s}}=-0.23, \mathrm{p}<0.001\right)$. Correlations between scores of all correlates tested are reported in the supplementary material. In total, residents were charted 3287 medications, which included 2235 regular medications and 1094 PRN medications. The most prevalent therapeutic subgroups were for analgesics ( $n=231$ residents) and drugs for constipation ( $\mathrm{n}=201$ residents). Tablets or capsules were the most common dosage form $(\mathrm{n}=1699, \quad 75 \%$ of regular medications) charted. Formulations with the highest proportion of residents in the "high" complexity group were nebulizers $(n=19 / 28$, $68 \%)$, aerolizers $(\mathrm{n}=8 / 12,67 \%)$, and pre-filled injections $(\mathrm{n}=11 / 17,65 \%)$. Two-thirds $(\mathrm{n}=1440,63 \%)$ of regular medications were charted for once-daily administration.
Over one-third of participants $(\mathrm{n}=86,36 \%)$ had five or more administration times per day. The median MRCI score was 42 . The frequency of medication administration contributed most to the overall MRCI score (Table 1 and Figure 2). Total MRCI score was positively correlated with number of daily administration times $\left(\mathrm{r}_{\mathrm{s}}=0.47\right.$, $\mathrm{p}<0.001$ ) (Figure 2). Section B of the MRCI had a stronger correlation with number of daily administration times $\left(r_{s}=0.56\right)$ than section $A\left(r_{s}=0.33\right)$ and section $C\left(r_{s}=0.27\right)$ (all $\mathrm{p}<0.001$ ).

Both number of daily administration times and MRCI score were positively correlated with length of stay in RACF $\left(r_{s}=0.185, p=0.004\right.$ and $r_{s}=0.265, p<0.001$, respectively), FRAIL-NH score $\left(r_{s}=0.231\right.$ and $r_{s}=0.335$, respectively, both $\mathrm{p}<0.001)$ and dependence in ADLs $\left(\mathrm{r}_{\mathrm{s}}=0.211\right.$ and $r_{s}=0.327$, respectively, both $\left.p<0.001\right)$. The MRCI score was weakly negatively correlated with CCI score $\left(r_{s}=-0.160, p=0.013\right)$ (Figures 3 and 4). There were no significant correlations between number of daily administration times and age $\left(\mathrm{r}_{\mathrm{s}}=0.01, \mathrm{p}=0.91\right)$ or DSRS score $\left(r_{s}=0.00, p=0.95\right)$; or MRCI and age $\left(r_{s}=0.02, p=0.74\right)$ or DSRS score $\left(\mathrm{r}_{\mathrm{s}}=-0.02, \mathrm{p}=0.79\right)$. 
Table I Baseline Characteristics Of SIMPLER Participants

\begin{tabular}{|c|c|}
\hline $\begin{array}{l}\text { Characteristic Median (Interquartile Range) } \\
\text { Unless Specified }\end{array}$ & Total $n=242$ \\
\hline Age in years & $87(8 I-92)$ \\
\hline Female; n (\%) & $179(74 \%)$ \\
\hline Rural; n (\%) & $48(20 \%)$ \\
\hline $\begin{array}{l}\text { Length of stay in the residential aged care facility } \\
\text { (RACF) in years }\end{array}$ & $2.5(1.0-4.7)$ \\
\hline Charlson Comorbidity Index (CCl) score ${ }^{a}$ & $2(2-3)$ \\
\hline Documented dementia diagnosis; $\mathrm{n}(\%)$ & $|3|(54 \%)$ \\
\hline Dementia Severity Rating Scale (DSRS) score ${ }^{\mathrm{b}, \mathrm{c}}$ & $21(11.8-38.3)$ \\
\hline Frailty in Nursing Homes (FRAIL-NH) score $\mathrm{e}^{\mathrm{b}, \mathrm{d}}$ & $7(3-10)$ \\
\hline $\begin{array}{l}\text { Katz Index of Independence in Activities of Daily } \\
\text { Living (Katz-ADL) })^{\text {be,f }}\end{array}$ & $I(I-3)$ \\
\hline Number of charted medications & $13(9-17)$ \\
\hline Regular & $9(6-12)$ \\
\hline Pro re nata (PRN) & $4(2-7)$ \\
\hline \multicolumn{2}{|l|}{$\begin{array}{l}\text { Most prevalent medications charted (ATC code); } \mathrm{n} \\
\text { (\% of residents) }\end{array}$} \\
\hline Paracetamol (N02BEOI) & $224(93 \%)$ \\
\hline Docusate with sennosides (A06AB56) & $145(60 \%)$ \\
\hline Macrogol (A06ADI5) & $103(43 \%)$ \\
\hline Colecalciferol (AIICC05) & 85 (35\%) \\
\hline Furosemide (C03CAOI) & $76(31 \%)$ \\
\hline $\begin{array}{l}\text { Number of medication administration times per } \\
\text { day }\end{array}$ & $4(3-5)$ \\
\hline $\begin{array}{l}\text { Medication Regimen Complexity Index (MRCl) } \\
\text { score }\end{array}$ & $42(28.5-55.5)$ \\
\hline Section A score (formulation) & $9(5-13)$ \\
\hline Section B score (frequency) & $19.8(14-26)$ \\
\hline $\begin{array}{l}\text { Section } C \text { score (special instructions for } \\
\text { administration) }\end{array}$ & $11(7-17)$ \\
\hline
\end{tabular}

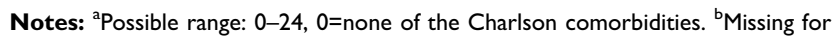
$\mathrm{n}=2$. 'Possible range: 0-54 (mild impairment, 0-18; moderate impairment, 19-36; severe impairment, 37-54). 'Possible range: 0-14 (non-frail, 0-I; frail, 2-5; most frail, 6-14). ${ }^{~}$ Possible range: 0-6 (dependence in all domains, 0 ; independence in all domains, 6). "When reversed to score for dependence: 5 (3-5).

Abbreviation: ATC, Anatomical Therapeutic Chemical.

In univariate logistic regression, length of stay was associated with both multiple medication administration times (OR: $1.10 ; 95 \%$ CI: 1.01-1.20) and high MRCI score (OR: 1.13; 95\% CI: 1.03-1.24) (Table 2). In the multivariate logistic regression model, FRAIL-NH score was associated with multiple medication administration times (OR: 1.13; 95\% CI: 1.03-1.24) and high MRCI score (OR: 1.26; 95\% CI: 1.13-1.41). The DSRS score was inversely associated with both multiple medication administration times (OR: 0.97; 95\% CI: 0.94-0.99) and high MRCI score (OR: 0.95; 95\% CI: 0.92-0.98).

\section{Discussion}

The main findings were that residents who were frailer and dependent in ADLs were more likely to have complex medication regimens when measured using number of daily administration times and MRCI score. To our knowledge, this was also the first study to establish the strong correlation between number of administration times and MRCI in RACFs. Effectively identifying residents with complex medication regimens is important to better target medication management interventions, such as medication regimen simplification, to particularly vulnerable residents. MRCI is likely to be time-consuming for clinicians to calculate in routine clinical practice unless incorporated into an electronic medication management system. In contrast, a count of daily administration times is easier for RACF nurses and other health professionals to measure and screen for medication regimen complexity.

Medication regimen complexity was positively correlated with frailty and dependence in ADLs. This was consistent with a previous study in Australian RACFs in which MRCI was associated with dependence in ADLs. ${ }^{40}$ Increasing frailty and dependence in ADLs may coincide with underlying changes in medical conditions which prompt prescribing of additional medications. Increasing frailty and dependence in ADLs may also necessitate changes to routes of administration (for example, crushed medications and mixing with thickened fluid to aid swallowing). Physicians and pharmacists may not proactively simplify medication regimens for frail residents and residents requiring assistance with ADLs for a number of reasons. Physicians and pharmacists may overestimate the capability and availability of RACF clinical staff to assess and simplify medication regimens. Similarly, there may be a perception that because residents are supported to take medications there is less need for simplification than in other settings. ${ }^{41}$ It is also possible that physicians and pharmacists do not fully recognize the complexity of a resident's medication regimen because they are not typically involved in medication administration. In a previous study, provision of a visualization of a patient's medication regimen for 1 week to the patient's treating physician was able to reduce medication regimen complexity by a mean of 2.47 (standard deviation, SD 1.55) doses per day in a hospital setting. ${ }^{26}$ 


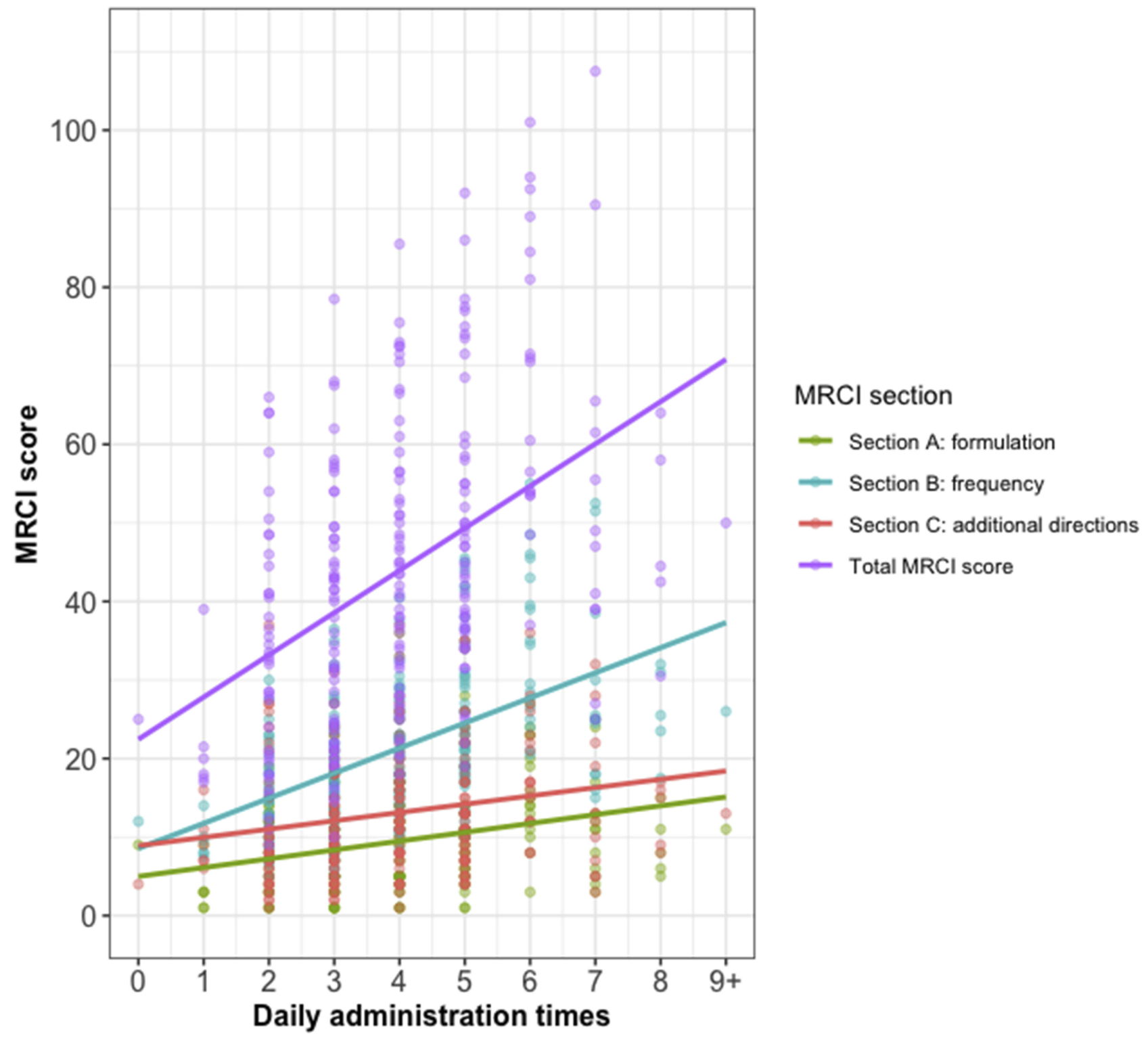

Figure 2 Scatter plot of Medication Regimen Complexity Index (MRCl) score versus daily administration times with linear regression lines.

Medication regimen complexity was positively correlated with length of stay. Over time, medications may be added and not ceased from the medication chart. Residents of RACFs may have multiple prescribers who are reluctant to discontinue medications prescribed by others. ${ }^{42}$ A previous German study reported that the number of PRN medications increased with length of stay. ${ }^{43}$ The Ageing@NH study of newly admitted residents to Belgian RACFs found an increase in the proportion of residents with extreme polypharmacy (the concomitant use of $>10$ medications) and residents using PRN medications over 2 years. ${ }^{44}$ Additionally, residents of Australian RACFs can be referred for government-funded collaborative medication reviews every 2 years unless more frequent reviews can be justified on the basis of clinical need. ${ }^{45}$ In these collaborative medication reviews, clinical pharmacists undertake a systematic, comprehensive medication review and evaluate medication management and make recommendations, such as ceasing medication or changing formulations, to the resident's primary physician for implementation. ${ }^{46}$ It has been estimated that $38 \%$ of all RACFs residents will receive a collaborative medication review annually. ${ }^{1}$ This means that residents with longer RACF stays may have up to 2 years between comprehensive medication reviews and may not have had a recent comprehensive medication review in which medication regimen complexity could have been addressed. 

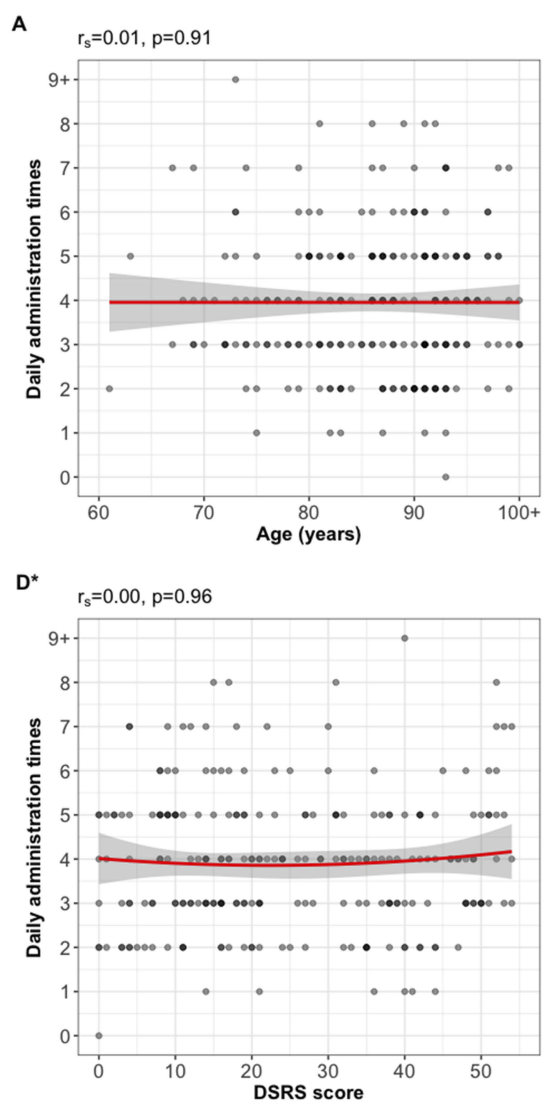

B

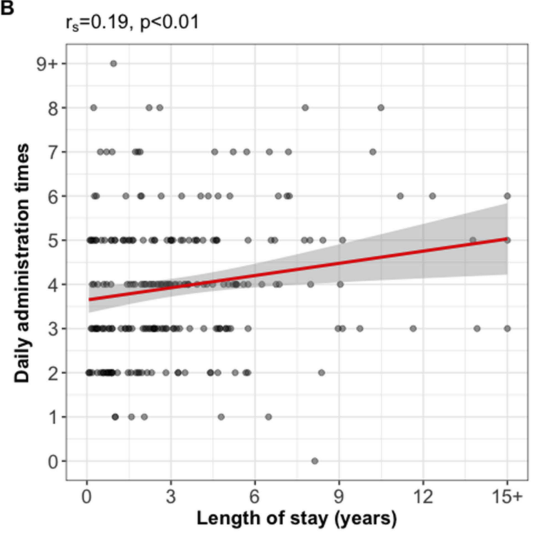

$E^{\star}$

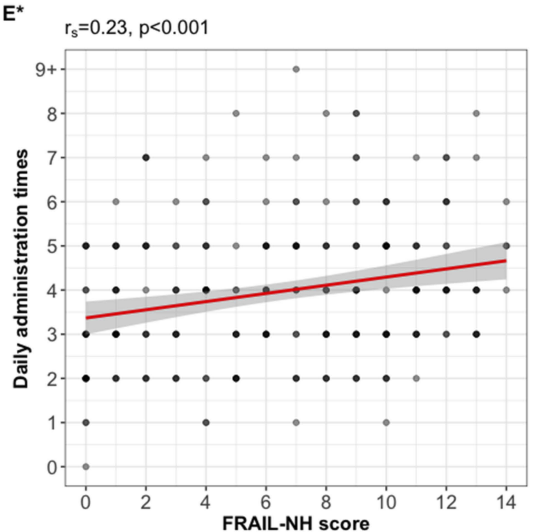

c

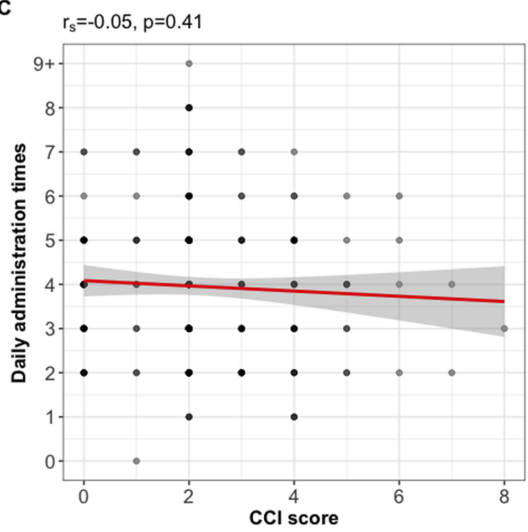

$F^{*}$

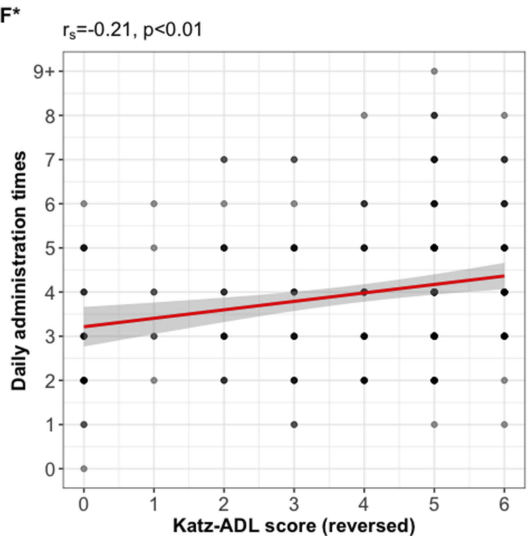

Figure 3 Plots of correlation of daily administration times with (A) age, (B) length of stay, (C) Charlson Comorbidity Index (CCI) score, (D) Dementia Severity Rating Scale (DSRS) score, (E) Frailty in Nursing Homes (FRAIL-NH) score, and (F) Katz Index of Independence in Activities of Daily Living (Katz-ADL) score, reversed to score for dependence. Solid lines: linear regression line; shaded areas: $95 \%$ confidence intervals. *Missing for $n=2$.

Our study found an inverse association between medication regimen complexity and dementia severity in multivariate analysis. Previous studies have reported residents with cognitive impairment are less likely to have complex medication regimens, ${ }^{40,47,48}$ and are less likely to experience polypharmacy, or the concomitant use of multiple medications (commonly $>8$ ). ${ }^{2,49}$ Recently, there has been focus in Australia on implementing a palliative approach to medication prescribing for residents with advanced dementia, and deprescribing for all older adults experiencing inappropriate polypharmacy. ${ }^{50,51}$ Deprescribing refers to reducing medications after consideration of therapeutic goals, benefits and risks, and medical ethics. ${ }^{52}$ Physicians may increasingly recognize the value of deprescribing medications for which the benefits no longer outweigh risks, especially in people with dementia and those who may have a shorter life expectancy. ${ }^{40,44,53}$ This finding may also be a reflection of documented undertreatment in people living with dementia, particularly in pain management. ${ }^{44,54}$

Medication regimen complexity was correlated with comorbidity when complexity was measured using MRCI but not daily administration times. This was unexpected because prescribing according to disease-based clinical practice guidelines has been described as a key contributor to polypharmacy and medication regimen complexity for people with multimorbidity. ${ }^{42}$ Our study found a median CCI score of 2, which was consistent with a previously published study in Australian RACFs. ${ }^{17}$ Residents with multimorbidity may have been more likely to have been referred for medication reviews, and may have a clinical need to receive medication reviews at more frequent intervals. This closer monitoring may help to decrease medication regimen complexity, although a retrospective study of comprehensive medication reviews for residents of RACFs did not find any significant impact on MRCI. ${ }^{37}$ Where pharmacists were given education and encouraged to simplify medication regimen, clinical medication reviews were found to reduce medication regimen complexity for older people in hospitals. ${ }^{55}$ We measured comorbidity using CCI, which does not measure total comorbidity. Previous studies have suggested that chronic pulmonary disease, diabetes, and congestive heart failure are particularly associated with higher MRCI score, 


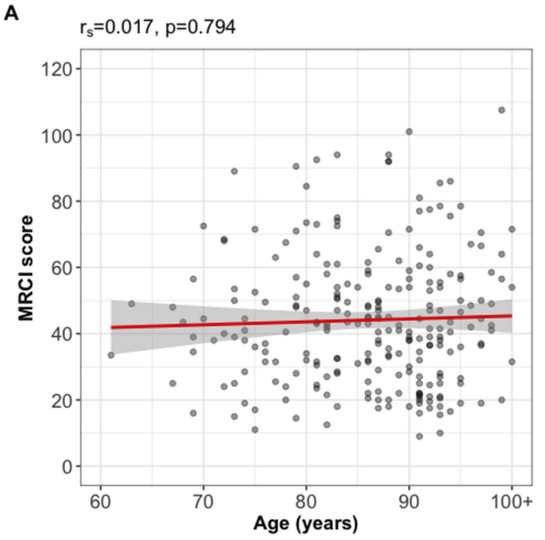

D*

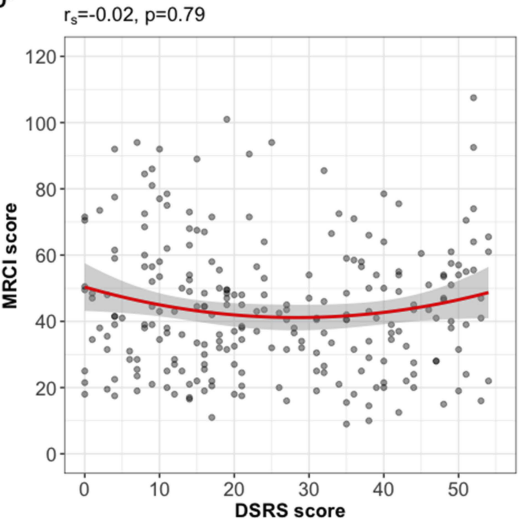

B

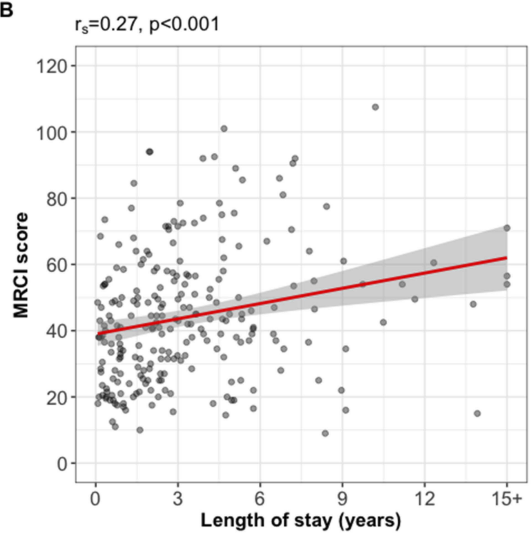

$E^{\star}$

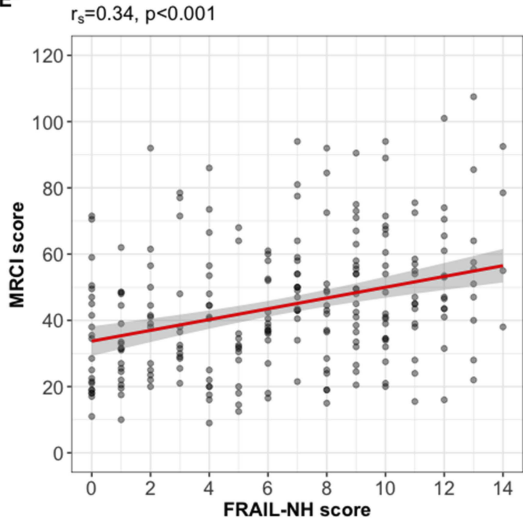

C

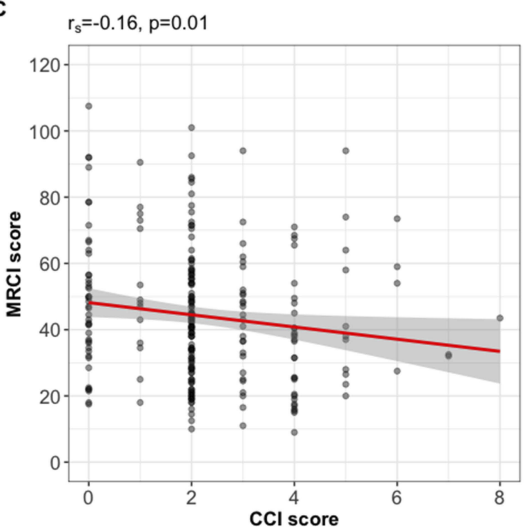

$F^{*}$

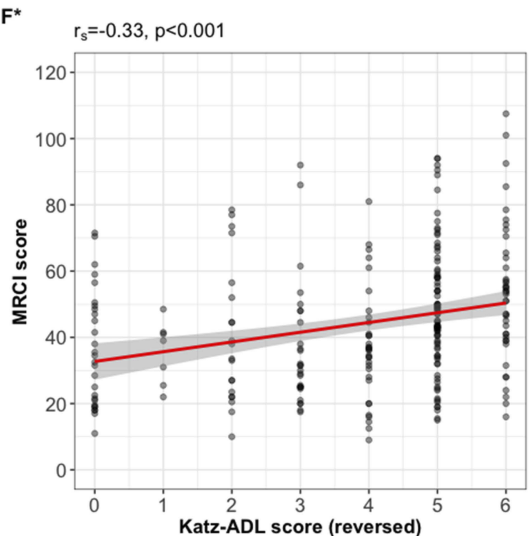

Figure 4 Plots of correlation of Medication Regimen Complexity Index (MRCl) score with (A) age, (B) length of stay, (C) Charlson Comorbidity Index (CCl) score, (D) Dementia Severity Rating Scale (DSRS) score, (E) Frailty in Nursing Homes (FRAIL-NH) score, and (F) Katz Index of Independence in Activities of Daily Living (Katz-ADL) score, reversed to score for dependence. Solid lines: linear regression line; shaded areas: $95 \%$ confidence intervals. *Missing for $n=2$.

while cognitive impairment is associated with lower MRCI scores. ${ }^{40,56}$ The CCI also does not include some medical conditions associated with medications that have frequent administration that may increase medication regimen complexity, such as Parkinson's Disease and chronic pain syndromes. ${ }^{22}$ However, it should be noted that complexity of medications for single conditions has not been found to be representative of overall complexity of the whole medication regimen, which often has medications to treat multiple conditions. ${ }^{57}$ Additionally, PRN medications are included when calculating MRCI score, whereas they were not included in a count of daily administration times. It is possible that PRN medications for symptom management may be more prevalent in residents with more medication conditions. Interventions to reduce complexity should be targeted to residents with conditions associated with higher MRCI but involve a full regimen review.

A previous validation study in Australian RACFs found that all residents with five or more administration times could have their medication regimens simplified. ${ }^{58}$ Medication simplification refers to:
The process of consolidating reducing medication complexity through strategies such as administering medications at the same time, standardizing routes of administration, using long-acting formulations in preference to shorter-acting agents, and switching from multiple single-ingredient preparations to a combination formulation where possible. ${ }^{27}$

A study of discharge prescriptions in Germany found that $18 \%$ of multidose medications could be simplified to oncedaily dosing. ${ }^{25}$ Regimen simplification may be valuable to complement other medication management interventions including medication reconciliation, review, and deprescribing. Our finding that over one-third of residents had five or more administration times suggests there is significant opportunity to reduce the number of administration times. Medication regimen simplification using structured tools $^{58}$ on or soon after admission to RACFs may be a useful strategy to reduce the number of administration times. Observation of 23 medication rounds across two Australian RACFs found that between 3.5 and 4.8 mins (SD 0.6-1.1) were spent on medication administration per 
Table 2 Univariate And Multivariate Logistic Regression Analysis

\begin{tabular}{|c|c|c|c|c|}
\hline & \multicolumn{2}{|c|}{ Multiple Medication Administration Times } & \multicolumn{2}{|l|}{ High MRCI Score } \\
\hline & $\begin{array}{l}\text { Unadjusted OR } \\
(95 \% \mathrm{CI})\end{array}$ & $\begin{array}{l}\text { Adjusted }^{\mathrm{a}} \text { OR } \\
(95 \% \mathrm{Cl})\end{array}$ & $\begin{array}{l}\text { Unadjusted OR } \\
(95 \% \mathrm{Cl})\end{array}$ & $\begin{array}{l}\text { Adjusted }^{\mathrm{a}} \text { OR } \\
(95 \% \mathrm{Cl})\end{array}$ \\
\hline Gender male & $0.65(0.34-1.20)$ & $0.71(0.36-1.36)$ & $0.50(0.22-1.03)$ & $0.59(0.25-1.28)$ \\
\hline Age (years) & $1.01(0.98-1.05)$ & $1.00(0.97-1.04)$ & $1.02(0.98-1.06)$ & $1.01(0.97-1.06)$ \\
\hline Length of RACF stay (years) & $1.10(1.01-1.20)$ & $1.09(0.99-1.20)$ & $1.13(1.03-1.24)$ & $1.10(1.00-1.22)$ \\
\hline $\mathrm{CCl}$ & $0.98(0.82-1.16)$ & $1.03(0.86-1.23)$ & $0.91(0.75-1.11)$ & $0.97(0.78-1.18)$ \\
\hline DSRS & $0.99(0.98-1.01)$ & $0.97(0.94-0.99)$ & $0.99(0.98-1.01)$ & $0.95(0.92-0.98)$ \\
\hline FRAIL-NH & $1.06(0.99-1.14)$ & $1.13(1.03-1.24)$ & $1.13(1.04-1.22)$ & $1.26(1.13-1.41)$ \\
\hline Katz-ADL & $0.90(0.77-1.03)$ & - & $0.81(0.67-0.96)$ & - \\
\hline
\end{tabular}

Note: ${ }^{a}$ Multivariate model did not include Katz-ADL due to collinearity with FRAIL-NH score.

Abbreviations: ADL, activities of daily living; $\mathrm{CCl}$, Charlson Comorbidity Index; Cl, confidence interval; DSRS, Dementia Severity Rating Scale; MRCI, Medication Regimen Complexity Index; OR, odds ratio; RACF, residential aged care facility.

resident per round. ${ }^{59}$ Reducing administration times would enable RACF staff to shift time spent administering medications to provision of other care activities, although further studies are required to determine how much time could be redirected towards other care activities as a result of simplifying medication regimens.

\section{Strengths And Limitations}

A strength of our study was that we extracted medication information directly from medication administration charts and so were able to accurately assess MRCI and administration times with high internal consistency, including all charted prescription and non-prescription medications. Although clinical diagnoses were extracted directly from medical records, we may have underestimated overall comorbidity using the CCI score because we only collected information about current diagnoses and because the CCI was developed to predict mortality and does not account for all diagnoses and their severity. However, the $\mathrm{CCI}$ has become widely used as a general measure of multimorbidity in the RACF setting.

An important strength of our study was the inclusion of a sample of residents that was representative of the wider resident population of the aged care provider organization in terms of age, sex and dementia diagnosis. ${ }^{60}$ However, we were not able to determine whether the sample was representative in terms of health status and medication use. The complexity of medication regimens in this study was higher than among residents who received medication reviews in Australia in 2011-12 (median MRCI score of 25.5); however, this may also be partly explained by an increase in polypharmacy over time. ${ }^{37}$ This study's median MRCI was also high when compared to studies in RACFs in Brazil and Portugal, although the participants were also younger and had lower rates of polypharmacy. ${ }^{15,16}$ These international studies did not include non-prescription medications. This may reflect the trend for Australian RACFs to cater to residents who have complex care needs or are most frail. ${ }^{42}$ Finally, only associations were investigated in this study; conclusions about causation cannot be made.

\section{Conclusion}

Residents of RACFs who were dependent in ADLs, had advanced frailty, and with longer lengths of stay were more likely to have the most complex medication regimens and, therefore, may benefit from targeted strategies to reduce medication regimen complexity. A count of daily administration times could be used to identify residents with these characteristics who may benefit from interventions to reduce medication regimen complexity.

\section{Data Sharing Statement}

Final data set access will be limited to study investigators. Other study-related documents, study protocol and model consent form have been previously published and can be accessed at https://www.anzctr.org.au/Trial/Registration/ TrialReview.aspx?id=372482.

\section{Acknowledgments}

The authors thank the staff and residents of Helping Hand Aged Care for their participation in this study. Thanks also extend to Jessica Bailey, Grace Wan, and Lina Ly for their assistance with data management.

\section{Disclosure}

This work was supported by the NHMRC Cognitive Decline Partnership Centre (grant number GNT9100000). The 
Cognitive Decline Partnership Centre receives support from the NHMRC and funding partners including Helping Hand Aged Care, HammondCare, Brightwater and Dementia Australia. The contents of the published materials are solely the responsibility of the individual authors identified, and do not reflect the views of the NHMRC and any other funding bodies or the funding partners. EYHC was supported by a postgraduate research scholarship funded by the Cognitive Decline Partnership Centre and the Monash University Faculty of Pharmacy and Pharmaceutical Sciences. JSB was supported by an NHMRC Dementia Research Leadership Fellowship. MC, MH and JvE are employed by Helping Hand Aged Care. JKS and JI were supported by NHMRC Early Career Fellowships. The authors report no other conflicts of interest in this work.

\section{References}

1. Sluggett JK, Ilomäki J, Seaman KL, Corlis M, Bell JS. Medication management policy, practice and research in Australian residential aged care: current and future directions. Pharmacol Res. 2017;116:20-28. doi:10.1016/j.phrs.2016.12.011

2. Jokanovic N, Tan ECK, Dooley MJ, Kirkpatrick CM, Bell JS. Prevalence and factors associated with polypharmacy in long-term care facilities: a systematic review. J Am Med Dir Assoc. 2015;16 (6):535.e531-535.e512. doi:10.1016/j.jamda.2015.03.003

3. George J, Phun Y-T, Bailey MJ, Kong DCM, Stewart K. Development and validation of the medication regimen complexity index. Ann Pharmacother. 2004;38(9):1369-1376. doi:10.1345/aph.1D479

4. Vogelsmeier A, Scott-Cawiezell J, Zellmer D. Barriers to safe medication administration in the nursing home - exploring staff perceptions and concerns about the medication use process. $J$ Gerontol Nurs. 2007;33(4):5-12.

5. Teunissen R, Bos J, Pot H, Pluim M, Kramers C. Clinical relevance of and risk factors associated with medication administration time errors. $\mathrm{Am} J$ Health Syst Pharm. 2013;70(12):1052-1056. doi:10.2146/ajhp120247

6. Szczepura A, Wild D, Nelson S. Medication administration errors for older people in long-term residential care. BMC Geriatr. 2011;11:82. doi: 10.1186/1471-2318-11-82

7. Barber ND, Alldred DP, Raynor DK, et al. Care homes' use of medicines study: prevalence, causes and potential harm of medication errors in care homes for older people. Qual Saf Health Care. 2009;18 (5):341-346. doi:10.1136/qshc.2009.034231

8. Gilmartin-Thomas JF, Smith F, Wolfe R, Jani Y. A comparison of medication administration errors from original medication packaging and multi-compartment compliance aids in care homes: a prospective observational study. Int J Nurs Stud. 2017;72:15-23. doi:10.1016/j. ijnurstu.2017.03.008

9. Keers RN, Williams SD, Cooke J, Ashcroft DM. Prevalence and nature of medication administration errors in health care settings: a systematic review of direct observational evidence. Ann Pharmacother. 2013;47(2):237-256. doi:10.1345/aph.1R147

10. Patel CH, Zimmerman KM, Fonda JR, Linsky A. Medication complexity, medication number, and their relationships to medication discrepancies. Ann Pharmacother. 2016. doi:10.1177/1060028016647067

11. Lalic S, Sluggett JK, Ilomäki J, et al. Polypharmacy and medication regimen complexity as risk factors for hospitalization among residents of long-term care facilities: a prospective cohort study. $\mathrm{J} \mathrm{Am}$ Med Dir Assoc. 2016;17(11):1067.e1061-1067.e1066. doi:10.1016/j. jamda.2016.08.019
12. Wimmer BC, Bell JS, Fastbom J, Wiese MD, Johnell $\mathrm{K}$. Medication regimen complexity and polypharmacy as factors associated with all-cause mortality in older people: a population-based cohort study. Ann Pharmacother. 2016;50(2):89-95. doi:10.1177/ 1060028015621071

13. Alves-Conceição V, Rocha KSS, Silva FVN, Silva ROS, DTd S, Lyra-Jr D. Medication regimen complexity measured by MRCI: a systematic review to identify health outcomes. Ann Pharmacother. 2018;52(11):1117-1134. doi:10.1177/106002801 8773691

14. Paquin AM, Zimmerman KM, Kostas TR, et al. Complexity perplexity: a systematic review to describe the measurement of medication regimen complexity. Expert Opin Drug Saf. 2013;12(6):829-840. doi:10.1517/14740338.2013.823944

15. Alves-Conceição V, Silva D, Santana V, Santos E, Santos LMC, Lyra D. Evaluation of pharmacotherapy complexity in residents of long-term care facilities: a cross-sectional descriptive study. BMC Pharmacol Toxicol. 2017;18(1):59. doi:10.1186/s40360017-0164-3

16. Advinha AM, de Oliveira-Martins S, Mateus V, Pajote SG, Lopes MJ. Medication regimen complexity in institutionalized elderly people in an aging society. Int J Clin Pharm. 2014;36(4):750-756. doi:10.1007/s11096-014-9963-4

17. Lalic S, Jamsen KM, Wimmer BC, et al. Polypharmacy and medication regimen complexity as factors associated with staff informant rated quality of life in residents of aged care facilities: a crosssectional study. Eur J Clin Pharmacol. 2016;72(9):1117-1124. doi:10.1007/s00228-016-2075-4

18. McDonald MV, Peng TR, Sridharan S, et al. Automating the medication regimen complexity index. $J$ Am Med Inform Assoc. 2013;20 (3):499-505. doi:10.1136/amiajnl-2012-001272

19. Olson CH, Dierich M, Adam T, Westra BL. Optimization of decision support tool using medication regimens to assess rehospitalization risks. Appl Clin Inform. 2014;5(3):773-788. doi:10.4338/ACI-201404-RA-0040

20. Wolf MS, Curtis LM, Waite K, et al. Helping patients simplify and safely use complex prescription regimens. Arch Intern Med. 2011;171 (4):300-305. doi:10.1001/archinternmed.2011.39

21. Lindquist LA, Lindquist LM, Zickuhr L, Friesema E, Wolf MS. Unnecessary complexity of home medication regimens among seniors. Patient Educ Couns. 2014;96(1):93-97. doi:10.1016/j. pec.2014.03.022

22. Richter A, Anton SE, Koch P, Dennett SL. The impact of reducing dose frequency on health outcomes. Clin Ther. 2003;25(8):23072335. doi:10.1016/s0149-2918(03)80222-9

23. Williams B, Shaw A, Durrant R, Crinson I, Pagliari C, de Lusignan S. Patient perspectives on multiple medications versus combined pills: a qualitative study. QJM. 2005;98(12):885-893. doi:10.1093/ qjmed/hci139

24. Witticke D, Seidling HM, Klimm HD, Haefeli WE. Do we prescribe what patients prefer? Pilot study to assess patient preferences for medication regimen characteristics. Patient Prefer Adherence. 2012;6:679-684. doi:10.2147/PPA.S35950

25. Witticke D, Seidling HM, Lohmann K, Send AF, Haefeli WE. Opportunities to reduce medication regimen complexity: a retrospective analysis of patients discharged from a university hospital in Germany. Drug Saf. 2013;36(1):31-41. doi:10.1007/s40264-0120007-5

26. Muir AJ, Sanders LL, Wilkinson WE, Schmader K. Reducing medication regimen complexity: a controlled trial. J Gen Intern Med. 2001;16(2):77-82. doi:10.1046/j.1525-1497.2001.016002077.x

27. Sluggett JK, Chen EYH, Ilomäki J, et al. SImplification of Medications Prescribed to Long-tErm care Residents (SIMPLER): study protocol for a cluster randomised controlled trial. Trials. 2018;19(1):37. doi:10.1186/s13063-017-2417-2 
28. Clark CM, Ewbank DC. Performance of the Dementia severity rating scale: a caregiver questionnaire for rating severity in alzheimer disease. Alzheimer Dis Assoc Disord. 1996;10(1):31-39.

29. Xie SX, Ewbank DC, Chittams J, Karlawish JHT, Arnold SE, Clark CM. Rate of decline in Alzheimer's disease measured by a dementia severity rating scale. Alzheimer Dis Assoc Disord. 2009;23(3):268274. doi:10.1097/WAD.0b013e318194a324

30. Katz S, Ford AB, Moskowitz RW, Jackson BA, Jaffe MW. Studies of illness in the aged: the index of ADL: a standardized measure of biological and psychosocial function. JAMA. 1963;185(12):914-919. doi:10.1001/jama.1963.03060120024016

31. Kaehr E, Visvanathan R, Malmstrom TK, Morley JE. Frailty in nursing homes: the FRAIL-NH scale. $J$ Am Med Dir Assoc. 2015;16(2):87-89. doi:10.1016/j.jamda.2014.12.002

32. Theou O, Sluggett JK, Bell JS, et al. Frailty, hospitalization, and mortality in residential aged care. J Gerontol A Biol Sci Med Sci. 2018;73(8):1090-1096. doi:10.1093/gerona/glx185

33. Theou O, Tan ECK, Bell JS, et al. Frailty levels in residential aged care facilities measured using the frailty index and FRAIL-NH scale. $J$ Am Geriatr Soc. 2016;64(11):e207-e212. doi:10.1111/jgs.14490

34. Quan H, Li B, Couris CM, et al. Updating and validating the charlson comorbidity index and score for risk adjustment in hospital discharge abstracts using data from 6 countries. Am J Epidemiol. 2011;173(6):676682. doi:10.1093/aje/kwq433

35. ATC/DDD Index [Internet]. Oslo: World Health Organisation Collaborating Centre for Drug Statistics Methodology; 2018.Available from: https://www.whocc.no/atc_ddd_index/. Accessed October 15, 2018.

36. GEN - Aged Care Data [Homepage on the Internet]. Canberra: Australian Institute of Health and Welfare; 2017. Available from: https://www.gen-agedcaredata.gov.au. Accessed November 15, 2018.

37. Pouranayatihosseinabad M, Zaidi TS, Peterson G, Nishtala PS, Hannan P, Castelino R. The impact of Residential Medication Management Reviews (RMMRs) on medication regimen complexity. Postgrad Med. 2018. doi:10.1080/00325481.2018.1502016

38. Borotkanics R, Rowe C, Georgiou A, Douglas H, Makeham M, Westbrook J. Changes in the profile of Australians in 77 residential aged care facilities across New South Wales and the Australian capital territory. Aust Health Rev. 2017;41(6):613-620. doi:10.1071/ AH16125

39. Residential Aged Care and Home Care 2013-14 [Internet]. Canberra: Australian Institute of Health and Welfare; 2015. Available from: http://www.aihw.gov.au/aged-care/residential-and-home-care-201314/. Accessed May, 2017. Accessed May 15, 2017.

40. Ferson M, Bell JS, Tan ECK, Emery T, Robson L, Wimmer BC. Factors associated with medication regimen complexity in residents of long-term care facilities. Eur Geriatr Med. 2015;6(6):561-564. doi:10.1016/j.eurger.2015.10.003

41. Elliott RA. Reducing medication regimen complexity for older patients prior to discharge from hospital: feasibility and barriers. $J$ Clin Pharm Ther. 2012;37(6):637-642. doi:10.1111/j.1365-2710. 2012.01356.x

42. Jokanovic N, Tan EC, Dooley MJ, Kirkpatrick CM, Elliott RA, Bell JS. Why is polypharmacy increasing in aged care facilities? The views of Australian health care professionals. J Eval Clin Pract. 2016;22(5):677-682. doi:10.1111/jep.12514

43. Dorks M, Schmiemann G, Hoffmann F. Pro re nata (as needed) medication in nursing homes: the longer you stay, the more you get? Eur J Clin Pharmacol. 2016;72(8):995-1001. doi:10.1007/ s00228-016-2059-4

44. Ivanova I, Wauters M, Stichele RV, et al. Medication use in a cohort of newly admitted nursing home residents (Ageing@NH) in relation to evolving physical and mental health. Arch Gerontol Geriatr. 2018;75:202-208. doi:10.1016/j.archger.2018.01.005
45. The Sixth Community Pharmacy Agreement. Residential Medication Management Review Programs (RMMR) and Quality Use of Medicines Program (QUM) Program Rules. Canberra; 2017.

46. Pharmaceutical Society of Australia. Guidelines for Pharmacists Providing Residential Medication Management Review (RMMR) and Quality Use of Medicines (QUM) Services. 2011.

47. Wimmer BC, Johnell K, Fastbom J, Wiese MD, Bell JS. Factors associated with medication regimen complexity in older people: a cross-sectional population-based study. Eur J Clin Pharmacol. 2015;71(9):1099-1108. doi:10.1007/s00228-015-1883-2

48. Lee DS, De Rekeneire N, Hanlon JT, et al. Cognitive impairment and medication complexity in community-living older adults: the health, aging and body composition study. J Pharm Technol. 2012;28 (4):156-162.

49. Morin L, Vetrano DL, Rizzuto D, Calderón-Larrañaga A, Fastbom J, Johnell K. Choosing wisely? Measuring the burden of medications in older adults near the end of life: nationwide, longitudinal cohort study. Am J Med. 2017;130(8):927-936.e929. doi:10.1016/j. amjmed.2017.02.028

50. Guideline Adaptation Committee. Clinical Practice Guidelines and Principles of Care for People with Dementia. Sydney: NHMRC Partnership Centre for Dealing with Cognitive and Related Functional Decline in Older People; 2016. Retrieved from: http:// sydney.edu.au/medicine/cdpc/documents/resources/dementia-guide lines final for\%20website.pdf. Accessed September 23, 2019.

51. Scott IA, Anderson K, Freeman CR, Stowasser DA. First do no harm: a real need to deprescribe in older patients. Med J Aust. 2014;201:390-392. doi:10.5694/mja14.00146

52. Turner JP, Edwards S, Stanners M, Shakib S, Bell JS. What factors are important for deprescribing in Australian long-term care facilities? Perspectives of residents and health professionals. BMJ Open. 2016;6(3):e009781. doi:10.1136/bmjopen-2015-009781

53. Schuling J, Gebben H, Veehof LJG, Haaijer-Ruskamp FM. Deprescribing medication in very elderly patients with multimorbidity: the view of Dutch GPs. A qualitative study. BMC Fam Pract. 2012;13:56. doi:10.1186/1471-2296-13-52

54. Reeve E, Bell J, Hilmer S. Barriers to optimising prescribing and deprescribing in older adults with dementia: a narrative review. Curr Clin Pharmacol. 2015;10(3):168-177.

55. Elliott RA, O'Callaghan C, Paul E, George J. Impact of an intervention to reduce medication regimen complexity for older hospital inpatients. Int J Clin Pharm. 2013;35(2):217-224. doi:10.1007/ s11096-012-9730-3

56. Bellostas-Muñoz L, Díez-Manglano J. Complexity of the medication regimen for polypathological patients. Rev Clin Esp. 2018;218 (7):342-350. doi:10.1016/j.rce.2018.04.009

57. Libby AM, Fish DN, Hosokawa PW, et al. Patient-level medication regimen complexity across populations with chronic disease. Clin Ther. 2013;35(4):385-398.e381. doi:10.1016/j.clinthera.2013.02.019

58. Chen EY, Sluggett JK, Ilomaki J, et al. Development and validation of the Medication Regimen Simplification Guide for Residential Aged CarE (MRS GRACE). Clin Interv Aging. 2018;13(1178-1998 (Electronic)):975-986. doi:10.2147/CIA.S158417

59. McDerby N, Kosari S, Bail K, Shield A, Peterson G, Naunton M. The effect of a residential care pharmacist on medication administration practices in aged care: a controlled trial. J Clin Pharm Ther. 2019. doi:10.1111/jcpt.12822

60. Hughes GA, Bell JS, Chen EY, et al. Would you like to participate? Factors impacting on participant recruitment for quality use of medicines interventions in residential aged care. Res Social Adm Pharm. 2019;15(5):e12. doi:10.1016/j.sapharm.2019.03.100 


\section{Publish your work in this journal}

Clinical Interventions in Aging is an international, peer-reviewed journal focusing on evidence-based reports on the value or lack thereof of treatments intended to prevent or delay the onset of maladaptive correlates of aging in human beings. This journal is indexed on PubMed Central, MedLine, CAS, Scopus and the Elsevier
Bibliographic databases. The manuscript management system is completely online and includes a very quick and fair peer-review system, which is all easy to use. Visit http://www.dovepress.com/ testimonials.php to read real quotes from published authors. 